\title{
Hein Kötz
}

\section{Vertragsrecht}

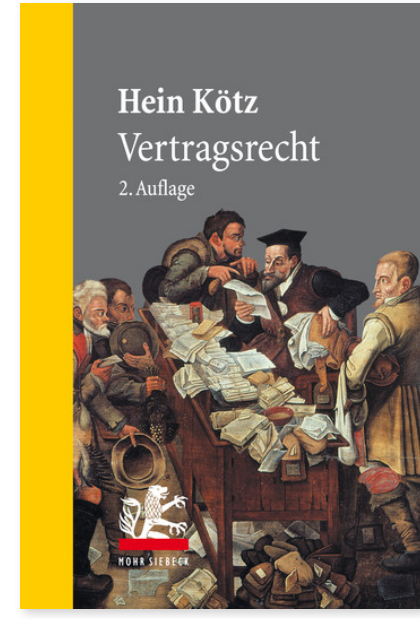

2., überarbeitete und aktualisierte Auflage; 2012. XXIII, 559 Seiten. MLB

ISBN 978-3-16-152194-2

DOI 10.1628/978-3-16-152194-2 eBook PDF $34,00 €$

ISBN 978-3-16-152065-5

fadengeheftete Broschur 34,00€
Wie kommt ein gültiger Vertrag zustande? Welche Pflichten werden durch einen Vertrag und durch die Aufnahme von Vertragsverhandlungen begründet? Nach welchen Regeln beurteilt es sich, ob eine Partei Erfüllung des Vertrages verlangen, den Vertrag durch Rücktritt, Widerruf oder Kündigung aufheben oder ihren Kontrahenten auf Schadensersatz in Anspruch nehmen kann? Hein Kötz geht im vorliegenden Band diesen und anderen Fragen des Vertragsrechts nach. Die 2. Auflage wurde gründlich überarbeitet.

Das Werk wurde zu den »juristischen Ausbildungsbüchern des Jahres 2009« gewählt.

Aus Rezensionen zur 1. Auflage:

»Der Gesamteindruck ist jedoch ohne Zweifel bestechend: ein großer Wurf!« Gostomzyk/Neureither/Norouzi JuS 2009, S. 1158 f.

"Neben den didaktischen und vertragstheoretischen Lorbeeren, die Kötz zuzusprechen sind, kommen dem Buch auch bedeutende systemanalytische Verdienste zu. [...] Die jetzt erschienene Erstauflage jedenfalls hat Pioniercharakter und ist als unverzichtbare Lektüre für alle Lernenden und Lehrenden zu begreifen, die sich 'am Puls der Zeit' mit dem Vertragsrecht befassen wollen.« Christoph Reymann Zeitschrift für Europäisches Privatrecht 2011, 739-742

»Wer Kötz' »Vertragsrecht " gelesen hat, ist zweifelsohne auf höchstem Niveau und hat neben dem unverzichtbaren Standardwissen auch wirtschaftliches und rechtsvergleichendes Verständnis zum Vertragsrecht gewonnen." Benjamin Krenberger studjur-online.de (1/2010)

Aus Rezensionen zur 2. Auflage:

»Es lässt sich wunderbar flüssig lesen und ist aufgrund der sehr guten Strukturierung auch zum schnellen 'Nachschlagen' geeignet."

Die ungekürzte Rezension von Sebastian Jäger finden Sie auf http://dierezensenten.blogspot.de/2013/02/rezensionzivilrecht-vertragsrecht.html (02/2013)

Für Bibliotheken gelten bei diesem Titel abweichende Konditionen; bitte wenden Sie sich an den Vertrieb.

Hein Kötz Geboren 1935; 1971-78 Professor an der Universität Konstanz; 1978-2000 Professor an der Universität Hamburg und Direktor am Max-Planck-Institut für ausländisches und internationales Privatrecht; 2000-04 Gründungspräsident der Bucerius Law School.

Jetzt bestellen:

https://mohrsiebeck.com/buch/vertragsrecht-9783161521942?no_cache=1

order@mohrsiebeck.com

Telefon: +49 (0)7071-923-17

Telefax: $+49(0) 7071-51104$ 